\title{
GAMBARAN PROSES PEMBUATAN DAN PENGGUNAAN TRANSFEMORAL PROSTESIS EKSOSKELETAL UNTUK AMPUTASI ATAS LUTUT KARENA KECELAKAAN KERJA
}

\author{
Nur Rachmat*1 ${ }^{*}$, Siska Meiwijayasmi ${ }^{2}$ \\ Poltekkes Kemenkes Surakarta Jurusan Ortotik Prostetik
}

\begin{abstract}
Background: Transfemoral exoskeletal prosthesis is an isntrument intervene in the form of a prosthesis fitted outside of the body that reverses the lower limb and can replace anatomical and functional functions. It is expected to provide satisfaction of amputee patient due work related accident. Methods: qualitative type with research methods used, namely interviews and observations. Results: manufacturing process of transdemoral exoskeletal prosthesis includes assessment, measurement, casting, fabrication, fitting, finishing. Conclusion: based of obsevations, interviews and analyzes carried out on tranfemoral prosthesis users, patiens now feel pious and happy to have progress in living activities using a prosthesis.
\end{abstract}

Keywords: Tranfemoral Amputasi,Work Accident, Transfemoral Exoskeletal Prosthesis

\section{PENDAHULUAN}

Kecelakaan industri adalah kejadian kecelakaan yang terjadi di tempat kerja khususnya di lingkungan industri. Menurut International Labour Organization (ILO) setiap tahun terjadi 1,1 juta kematian yang disebabkan oleh penyakit atau kecelakaan akibat hubungan pekerjaan. Sekitar 300.000 kematian terjadi dari 250 juta kecelakaan dan sisanya adalah kematian akibat penyakit akibat hubungan pekerjaan. Data dari Dewan Keselamatan dan Kesehatan Kerja Nasional (DK3N) menunjukkan bahwa kecenderungan kejadian kecelakaan kerja meningkat dari tahun ke tahun yaitu 82.456 kasus di tahun 1999 meningkat menjadi 98.905 kasus di tahun 2000 dan naik lagi mencapai 104.774 kasus pada tahun 2001. Dari kasus-kasus kecelakaan kerja $9,5 \%$ diantaranya (5.476 tenaga kerja) mendapat cacat permanen. Ini berarti setiap hari kerja ada 39 orang pekerja yang mendapat cacat baru atau rata-rata 7 orang meninggal karena kecelakaan kerja.

World Health Organization (WHO) memperkirakan terdapat 40 juta pasien amputasi diseluruh negara berkembang. Angka kejadian amputasi yang pasti di Indonesia tidak diketahui menurut vitriana (2002) di Amerika serikat terjadi 43.000 kasus pe tahun dari jumlah penduduk 280.562.489 jiwa atau sekitar 0,02\% sedangkan dalam raichle et al. (2008) disebutkan bahwa terjadi kasus amputasi sekitar 158.000 per tahun dari jumlah penduduk 307.212.123 atau sekitar 0,05\% (jumeno, 2009).

Amputasi sebagian anggota gerak akan menyebabkan ketidakmampuan seseorang untuk melakukan aktivitas dalam derajat yang bervariasi, tergantung bagian anggota gerak yang teramputasi, usia, dan penanganan operasi (Berke, 2008). Amputasi dapat disebabkan oleh berbagai hal diantaranya penyakit, trauma, infeksi, tumor, conginetal. 
Amputasi pada level transfemoral sangat menantang untuk pasien melakukan operasi, prosthetist, physiotherapist, dan setiap anggota tim kesehatan di united states, level amputasi ini paling dikenal sebagai amputasi lain, amputasi ini dikenal amputasi transfemoral karena amputasi ini terjadi dipaha yang melalui tulang femur (ulger,2009).

Penggunaan alat berupa prosthesis berkaitan erat dengan kepuasaan pasien yang pada akhirnya memberikan perasaan senang yang timbul karena hasil yang pasien dapatkan sesuai dengan yang pasien harapkan (Kotler and Kaller, 2008). Kepuasaan pasien adalah respon pasien terhadap apa yang telah dirasakan antara harapan sebelumnya dan hasil kinerja yang didapatkan setelahnya (Tjiptonno, 2006).

Transfemoral prosthesis merupakan kaki tiruan yang digunakan untuk amputasi atas lutut. Individu dengan amputasi atas lutut sulit akan mengembalikan gerakan normal. Secara umum, individu dengan amputasi atas lutut harus menggunakan $80 \%$ lebih banyak energy untuk berjalan daripada seseorang yang masih memiliki tungkau normal. Hal ini disebabkan komplesipitas gerakan yang terjadi pada lutut. Untuk proses pembuatan transfemoral prosthesis meliputi: (1) assessement, (2) measurement, (3) casting, (4) fabrikasi, (5) fitting, (6) finishing. Tahapan fabrikasi terdiri dari rektifikasi begative cast, filling, rektifikasi positif cast, laminasi (Barke, 2008). Untuk itu peneliti tertarik untuk meneliti gambaran proses pembuatan dan penggunaan transfemoral prostesis eksoskeletal untuk amputasi atas lutut karena kecelakaan kerja

\section{METODE PENELITIAN}

Penelitian ini menggunakan penelitian kualitatif. Penelitian kualitatif menghasilkan dan mengolah data yang bersifat deskriptif. Metode penelitian yang digunakan dalam penelitian ini adalah penelitian ini dilakukan dengan studi kasus yang bersifat intrinsik, yaitu kasus yang diambil merupakan kasus yang menarik untuk diteliti. Menurut Moleong (1998). Sedangkan menurut Moleong (2000) pendekatan kualitatif adalah pendekatan yang bermaksud untuk memahami fenomena tentang apa yang dialami oleh subjek penelitian misalnya perilaku persepsi, motivasi, tindakan dan lain- lain.Peneliti akan melakukan penelitian kualitatif dengan metode pengumpulan data secara wawancara terfokus (Poerwandari. 2001). Dimana subjek penelitian ini pasien amputasi transfemoral dengan cara wawancara terfokus langsung pada pasien yang bersangkutan.

\section{Metode Pengumpulan Data}

Teknik pengumpulan data yang akan digunakan dalam penelitian ini adalah wawancara dan observasi. Pada penelitian ini, peneliti melakukan observasi di tempat tinggal pasien. Peneliti melakukan observasi pada pasien amputasi saat menjalankan aktivitas sehari-hari menggunakan transfemoral prosthesis. Observasi dilakukan untuk mengamati segala aktivitas pasien amputasi transfemoral di lingkungan tempat tinggalnya. Menurut Carwright (1984), tujuan dilakukannnya observasi adalah untuk mengamati dan merekam informasi tingkah laku yang dilakukan secara sistematis 


\section{HASIL PENELITIAN}

Subjek penelitian ini adalah satu pasien laki-laki penyandang amputasi transfemoral karena kecelakaan kerja dengan menggunakan tranfemoral prostesis eksoskeletal yang berumur 47 tahun, pekerjaan sebagai karyawan swata, hobi ngobrol, lokasi yogyakarta dan amputasi kaki kanan pada tahun 2005 . Sedangkan kelas ekonomi pasien pada golongan miskin. Transfemoral prostesis adalah alat ganti tungkai bawah untuk pasien yang mengalami amputasi sampai tulang femur (Barke,2008). Untuk pembuatan prostesis melalui beberapa tahapan yaitu assessment, yang mana proses wawancara masuk dalam tahapan ini dan hasil wawancara kami mengetahui kondisi pasien meliputi kekuatan otot (MMT) dan luas gerak sendi (ROM) didapat dari tahap ini. Untuk alat yang digunakan adalah blanko ukur, alat tulis, dan goneometer (CSPO,1999).

Tahapan yang kedua adalah pengukuran (measurement) stump pasien dari sisi tungkai yang normal. Sebelum dilakukan pengukuran, dilakukannya penandaan pada stump. Selanjutnya pengukuran pada stum. Lalu dilakukan pengukuran pada sisi tungkai yang normal untuk menjadi patokan saat merangkai prosthesis diukur dalam posisi berdiri. Tahapan ketiga adalah tahapan pengambilan cetakan stump pasien(casting)yang nantinya akan menghasilkan negative cast. Sebelum dilakukan casting memberikan pengarahan dan sedikit penjelasan kepada pasien tentang proses apasaja yang akan dilakukan, sehingga pasien dapat mengikuti proses dengan baik dan tidak menyinggung privasi pasien Selama proses casting pasien dalam posisi berdiri dan sebelum dibalutkan P.O.P lakukan latihan hand position untuk mengetahui gambaran letak dari ischial tuberosity dan gambaran posisi tangan yang membentuk quadrilateral socket .

Dalam pembalutan P.O.P bandage dilakukan menggunakan teknik slab dan wrapping, untuk teknik slab lakukan pengukuran panjang P.O.P bandage dari adductor tendon sampai melingkupi bagian atas trochantor mayordengan ketebalan 3- 4 lapis. Pada bagian tengah P.O.P bandage, buat notch dengan lebar 4 $\mathrm{cm}$. Selanjutnya rendam P.O.P bandage dalam air dan peras kemudian balutkan pada stump pasien dari adductor tendon sampai bagian atas trochantor mayor (horizontal). Pastikan notch berada pada aductor tendon. Selanjutnya menggunakan teknik wrapping, yaitu rendam P.O.P Bandage dalam air ,kemudian peras dan balutkan memutar mulai dari pelvis ke bagian distal stump dengan ketebalan 3 lapis, massage. Lakukan penekanan pada ischial tuberosity, medial wall dan scarpa triangle untuk membentuk quadrilateral dan penekanan pada 1/3 proksimal lateral untuk memberikan lateral support. Dan alignment pada negative cast dengan menggunakan plumb line pada anterior wall dan lateral wall untuk mengetahui sudut fleksi dan abduksi stump dan tandai menggunakan pensil air. Lepaskan negative cast dari stump pasien dan lakukan pengecekkan supaya mengetahui kekurangan dari negative cast dan perbaikkan yang harus dilakukan.

Tahapan keempat fabrikasi yang merupakan proses pembuatan socket, baik hard socket maupun soft socket. Dalam tahapan ini meliputi rektifikasi negative cast, filling negative cast, rektifikasi positif cast, laminasi, assembling dan alignment. Tahap rektifikasi cast 
bertujuan untuk memudahkan membentuk quadrilateral dan mengetahui apakah cast sudah memiliki bentuk dan simetri yang tepat di medio-lateral axis. Yang dilakukan dalam tahapan ini, adalah mengecek ukuran negative cast dan lakukan penandaan ulang, Potong trimeline sesuai garis yang telah dibuat saat pengecekan cast, lakukan penambahan di posterior wall untuk membentuk ischial seat. Pastikan sudut luar antara dinding medial dan posterior membentuk sudut $90^{\circ}$. Melakukan rektifikasi pada medial wall : 1/3 proksimal dibuat flat dan vertical, Proksimal medial wall dibuat turun 0,5 $\mathrm{cm}$ untuk pubis ramus dan adductor tendon. Melakukan rektifikasi pada posterior wall : Bentuk sudut $100^{\circ}$ (antara dinding medial dan posterior ), Ischial seat dibuat horizontal dan flat. Rektifikasi pada anterior wall : penambahan pada segitiga scarpa, bagian proksimal dibuat flare / melengkung ke luar. Rektifikasi pada lateral wall : lakukan penambahan pada 1/3 proksimal (di atas trochantor mayor), bagian proksimal dibuat flare I melengkung ke luar. Sesuaikan diameter A-P cast, sesuaikan diameter M-L cast, sesuaikan sudut fleksi, Sesuaikan sudut adduksi, yang perlu diperhatikan adalah tuberositas isia diposisikan 1,5-2,5 cm lateral dari medial wall, tendon adductor longus berada pada sudut antara medial dan anterior wall, cekungan pada anterior femoral triangle selevel dengan ischia tuberositi titik terdalamnya ada pada segitiga medial wall.

Selanjutnya tahap filling negative cast dengan campuran adonan dari gipsum powder dan air. Setelah hasil filling mengeras, membuka cetakan negative cast dan menghasilkan cetakan berupa positif cast. Tandai ulang di positif cast dan mengukur ulang dan bandingkan dengan blanko ukur. Tahapan selanjutnya rektifikasi positif cast, dengan pengurangan pada daerah pressure tolerant area, dan penambahan pada pressure sensitive area.

Selanjutnya membuat body shank, sebelumnya sudah mengambil cetakan tungkai bawah pasien pada sisi yang normal. Lalu hasil cetakan di cor menggunakan powder gips dengan campuran air, setelah itu buka hasil pengecoran lalu dirapikan. Setelah itu ukur kembali circum terbesra dan terkecil dan sesuaikan bentuk dengan tungkai pasien. Tahap laminasi, tahapan yang menghasilkan hard socket yang terbuat dari resin, fiber glass, stockinet. Setelah tahap laminasi lakukan pembuatan trimline dan lepaskan hard socket dari positif cast menggunakan cast cutter. Selanjutnya tahap penyusunan komponenkomponen dan bench Alignment yang bisa dilakukan sesuai dengan kondisi pasien tersebut adalah sebagai berikut socket adduksi 5०, alignment socket pada pandangan anterior adalah $60 \%$ lateral dan $40 \%$ medial, alignment socket pada pandangan lateral adalah $50 \%$ anterior dan $50 \%$ posterior, knee axis $1,5-2 \mathrm{~cm}$ di depan TKA line, knee axis $2 \mathrm{~cm}$ di atas MTP, foot $5 \circ-7 \circ$ external rotasi atau sesuai dengan line of progression. Tahap

kelima adalah fitting atau pengepasan alat ketubuh pasien saat berdiam (static alignment), yang perlu di check pas tidaknya socket, mengecek bench alignment dan mengecek panjang prosthesis baik saat menggunakan prosthesis yang baru atau yang lamadan saat pasien berjalan menggunakan prosthesis (dynamic alignment). Gambar 1. Menunjukkan pasien menggunakan 
Transfemoral Prosthesis saat static alignment.

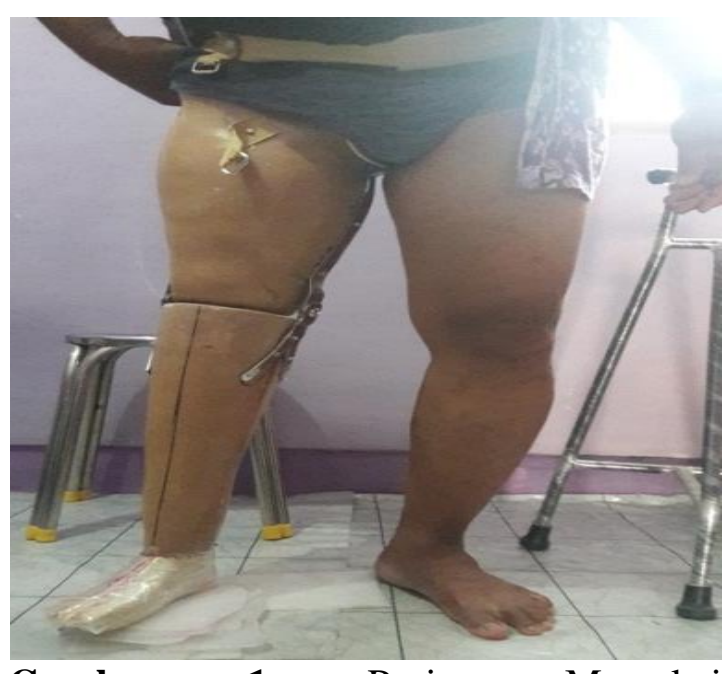

Gambar 1. Pasien Memakai Transfemoral Prosthesis Exoskeletal

Selanjutnya tahap keenam adalah finishing. tahapan yang dilakukan setelah semua tahapan selasai dengan tujuan untuk memperindah dalam segi kosmesisnya dan dilakukan sebelum prosthesis diserahkan kepada pasien.

\section{PEMBAHASAN}

Dalam analisa ini terdapat gambaranumum subjek, hasil observasi pemakaian transfemoral prsotesis eksoskletal dan hasil wawancara dengan subjek dan opis tentang kondisi pasien sebelum dan sesudah menggunakan transfemoral prostesis eksoskeletal.

1. Gambaran umum subjek

Tn. JK berumur 47 tahun, timpat tinggal dilingkungan Pungkuran, Bantul Yogyakarta. Penyebab amputasi pasien yakni kecelakaan kerja pada tahaun 2005 disaat pasien sedang melaksanakan kerja pasien terjatuh dari loteng. Pada awalnya pasien terjatuh diatas asbes, namun asbes tersebut tidak bisa menopang badan pasien yang akhirnya pasien terjatuh hingga kedasar lantai, dimana didasar lantar terdapat banyak pecahan kaca yang mengakibatkan pada bagiang tungkai bawah pasien tertusuk. Trauma yang cukup parah yaitu pendarahan yang hebat dan tulang bagian tungkai bawah hancur. Proses perawatan di rumah sakit selama satu bulan setengah dan ternyata pada bagian otot tungkai bawah ada yang pembusukan dan pembuluh darah membengkak sampai tungkai atas. Kerusakan jaringan ini mengharuskan tungkai pasien untuk di amputasi pada daerah tulang femur. Menurut penelitian ratih damayanti (2018) Kecelakaan kerja disebabkan oleh perilaku tidak aman dan kondisi yang tidak aman. Faktor yang erat kaitannya dengan perilaku tidak aman terkait dengan karakteristik individu adalah usia kurang dari 45 tahun, masa kerja pekerja lebih dari 10 tahun, dan tingkat pendidikan yang rendah. Setelah di amputasi pasien menjalani perawatan selama 2 bulan, setelah itu pulang ke rumah. Sekarang juga pasien nyaman menggunakan prostesis dalam seluruh aktivitasnya yaitu bekerja sebagai karyawan swasta dan mengikuti segala authing class bersama kumpulan difabel ke alam maupun sosial.

\section{Analisis Alat Hasil Observasi Penggunaan Transfemoral Prostesis Eksoskeletal. \\ Dari hasil observasi penggunaan} transfemoral prostesis eksoskeletal dapat dilihat bahwasanya pasien merasa puas dan percaya diri lagi karena memiliki kembali tungkainya yang hilang. Menurut penelitian jared asher sartee (2009) bahwasanya seorang pengguna transfemoral prostesis eksoskeletal akan lebih kecil kemungkinannya mengalami 
jatuh yang tergelincir pada persendian lutut.

Sebelum memakai alat, terkadang pasien menyadari hala - hal negatif tentang dirinya yang dibandingkan dengan orang lain dan juga mersa aneh saat melihat dirinya sendiri. Meskipun pasien dalam kesehariannya pasien tidak pernah merasa rendah diri dan selalu mendapatkan dukungan dari banayk orang yang juga mengalami seperti dirinya namun sesekali itu yang dirasakan oleh pasien. Kemudian setelah menggunakan dan belajar bagaiaman cara pemakaian prostesis pasien merasa lebih baik dan optimis ketika berkativitas di luar rumah.

Berdasarkan penelitian kepuasan pengaruh terhadap loyalitas pelanggan sehingga semakin tinggi kepuasaan pelanggan maka loyalitas pelanggan juga semakin meningkat. Menurut Basuth et, al. (2014) menyatakan bahwa semakin tinggi kepuasaan yang diterima oleh pelanggan maka semakin besar pula pelanggan tersebut menjadi loyal. Secara umum kepuasaan adalah perasaan senang atau perasaan kecewa seseorang yang kuncul setelah membandingkan hasil yag dipikirkan dengan hasil yang didapatkan.

Ketika pasien melakukan proses latihan menggunakan prostesis yang dibuatkan ini tidak banyak penyimpangan pola jalan yang diperoleh pasien. Pola jalannya cukup baik dan yang terpenting pasien merasa nyaman saat melangkahkan kakinya walaupun itu baru kali pertama pasien menggunakan prostesis dengan kondisi teramputasi. Waktu yang dibutuhkan pasien untuk melakukan pelatihan pemakaian dan berlatih jalan agar seperti oatng normal juga relatif singkat. Sampai saat ini pasien sudah mengganti prostesis sebanyak 5 kali.

\section{KESIMPULAN DAN SARAN}

Berdasarkan hasil observasi, wawancara dan analisa yang dilakukan terhadap penggunaan transfemoral prostesis eksoskeletal, kini pasien merasa sangat puas dan senang, ada kemajuan dalam beraktivitas berkat penggunaan prostesis terlebih di tempat umum. Dalam proses pembuatan alatnya dan pelatihan berjalan, pada pasien tidak ditemui pola jalan yang bermasalah dan pasien sudah merasakan nyaman pada saat berdiri maupun berjalan dengan menggunakan prostesis. Maka dapat disimpulkan, bahwa penggunaan transfemoral prostesis eksoskeletal dapat membantu memberikan kepuasaan dan semangat dengan menggatikan tungkai pasien yang hilang akibat amputasi yang disebabkan oleh kecelakaan kerja.

Adapun saran yang dapat diberikan oleh peneliti yakni sebaiknya pasien yang mengalami amputasi dibuatkan alat gerak ganti untuk mengembalikan bagian yang telah hilang. Karena selain untuk memberi kepuasaan pada pasien, prostesis juga membantu secara anatomis dan fungsional dalam beraktivitas.

\section{DAFTAR RUJUKAN}

Badan Pusat Statistik. 2012. Jumlah Kecelakaan, Korban Mati, Luka Berat, Luka Ringan, dan Kerugian Materi yang Diderita Tahun 19922012. Dikutip 11 Januari 2016, dari http://bps.go.id/tab_sub/view.php?k at $=2 \&$ tabel $\quad=1 \&$ daftar $=1 \&$ id subyek $=17 \&$ notab $=14$.

Meleong, J.L 2000. Metodologi Penelitian Kualitatif (Edisi Revisi). Bandung: PT. Remaja Rosdakarya. 
Patton. Q. M 2002. Qualitative research and evaluation metode, 3 nd ed. California: Sage Publication, Inc.

Permenkes RI. 2013. Pengertian Ortotik Prostetik: 22.

Poerwandari, K. 2001. Pendekatan Kualitatif Untuk Penelitian Perilaku Manusia. Jakarta : Lembaga Penegmbangan Sarana Pengukuran \& Pendidikan Psikologi (LPSP 3) Universitas Indonesia.

Arelekatti, V.N.M. 2016. Design and Perry Preliminary Field Validation of a Fully Passive Prosthetic Knee Mechanism for Users with Transfemoral Amputation in India. ASME Journal of Mechanisms and Robotics.

Basuki, A. M. H. 2006. Penelitian Kualitatif untuk ilimu-ilmu kemanusiaan dan budaya. Jakarta : Gunadarma

Berke, G. M. Et,al, 2008: Transfemoral Amputaton: The Basic and Bayond. Ottobock Healthcare LP And Prostethic Reserch Study.

Pauley, T., Delvin , M, Helsin, K. Falls 2006. Susteined during inpatient rehabititaion after lower limbamputation : prevalence and predictors. Am J Phys Med Rehabil. 2006; $85: 521-532$

Jared Asher sartee, 2009. Design and tasting of a low-cost exoskeletal trans femoral prosthesis knee device for use in developing countries

Muhammad fathi, et. Al, 2017. Analisis kualitas produk dan pelayanan kaki palsu terhadap kepuasaan dan loyalitas pelanggan.

Ratih damayanti, et. Al 2018. Gambaran kecelakaan kerja di industri baja $\mathrm{x}$ gersik indonesia.
Gabbiadini S. Knowledge-based design of lewerlimb prosthesis. University Degli Studi Di Padove 2001;113122 http://paduaresearch. Cab .unipd.it /3 